\title{
POST-MORTEM ANALYSIS ON THE ANALYSIS AND EVALUATION OF RISKS IN CONSTRUCTION PROJECT MANAGEMENT
}

\author{
Martin Schieg \\ University of Applied Sciences Augsburg, Baumgartnerstrasse 16, 86161 Augsburg, Germany \\ E-mail: martin.schieg@cbp.de
}

Reiceived 16 October 2006; accepted 21 March 2007

\begin{abstract}
Risk management is used more and more in building industry projects. An essential element of the risk management process is the analysis and evaluation of risks. Therefore, project assessment with the help of the post-mortem analysis plays an important role. The post-mortem analysis is a tool frequently used in software projects today for the reduction of risks. The clearness of the goal of improvement measures is sharpened by the examination of the project steps in connection with the success factors of the organization. The results of a post-mortem analysis deliver detailed information on where improvement measurements are necessary in the project future. Growth in project management know-how is created through the discussion of the participants of all hierarchy levels. Therefore, the post-mortem analysis is also applicable for use in the construction project. The procedure is introduced in the work at hand.
\end{abstract}

Keywords: Risk management process, risk identification, risk evaluation, project management, post-mortem analysis, Ishikawa method, knowledge management, root cause analysis, knowledge management.

\section{Introduction}

Risk management has grown in significance in the companies of the building industry. Intense competition compels them to deal intensively with the analysis of opportunities and risks. The analysis of errors in repetitive processes plays an essential role in the evaluation of risks. Methods such as the post-mortem analysis are used in production as a standard for the further development and optimization of operations and, for this reason, for the reduction of risks. It is fundamentally more difficult to learn from projects since every project is unique in itself. The analysis of processes, the assessment of projects, the discovery of the need for improvement and the implementation of complex alterations of the process are the core tasks of company management.

One tool for this is the post-mortem analysis. It is used today especially in IT projects; the terms "project retrospective" and "project review" are also found in the literature for this.

The post-mortem analysis is a tool for company knowledge management. In every project, the team members gain new knowledge and experiences that support future projects and broaden the knowledge of the individual employee. This knowledge must be incorporated in the risk management process. It is, e.g., integrated into check lists for the identification of project risks. Risk evaluation is simplified and made more accurate by the compilation of results from preliminary projects. Typical answers emerge from the questions:

What problems have arisen, how did problems come about, what reactions do these lead to, what costs have emerged and what risks remain.

Before findings from a project can be used for new projects, ways must be found to bring them together and to consolidate the information. For example, project information packets can be tied together, which can be held in databanks and used by other employees.

The end of a project is the appropriate time to set reasonable standards, to analyze and to apply concrete data that can be drawn on in the planning of future activities. 
In doing so, successes as well as errors should be analyzed and consistent opportunity and risk management pursued for future projects.

The following shows how the post-mortem analysis (PMA) can be used in the risk management of construction projects.

\section{Risk management in projects}

Risk management includes the integration of riskpolitical principles, the establishment of risk consciousness as well as organizational integration. It is the impetus for the risk management process and is responsible for risk control with knowledge of the current risk situation [1]. Risk management increases transparency; proactive handling can prevent many problems beforehand and the project can be prepared for unavoidable problems. Outcomes can be moderated and the project manager retains control of his project.

\subsection{The risk management process}

The risk management process includes several steps that are explained below and are represented in Fig 1 [2].

\subsubsection{Identifying risks}

Risks that are not recognized can not be evaluated and dealt with. However, complete ascertainment of risks is impossible. It is therefore the task of risk management to ascertain the fundamental risks as completely as possible.

\subsubsection{Analyzing risks}

The objective is to describe the risk situation as completely and accurately as possible and to prioritize the risks. For this purpose, the identified risks related to the occurrence probability and the effects on the

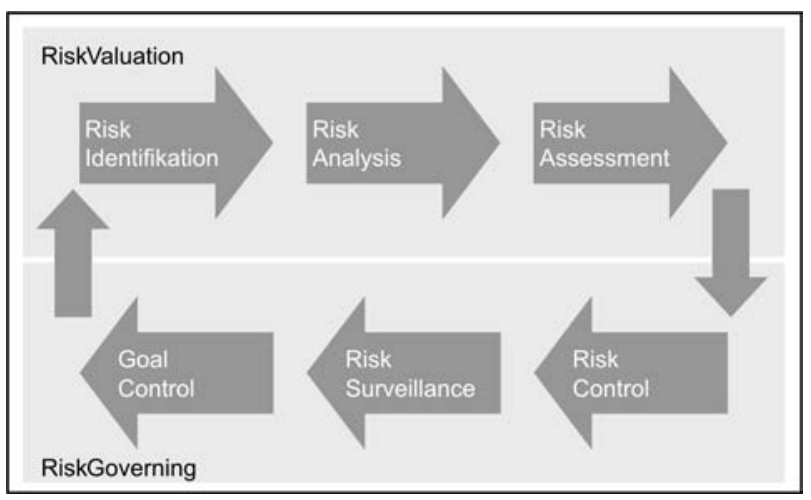

Fig 1. The Risk Management Process project are examined. A portfolio and/or risk cost evaluation predominantly serve for classification. Standards must be found based on which individual risks can be evaluated and compared with one another.

\subsubsection{Evaluating risks}

A risk must always be described as a loss occurrence to which a total defined value can be assigned. A value for the risk can be calculated from this loss evaluated according to cost and the occurrence probability.

The risk evaluation contains the qualitative evaluation and quantitative measurement of individual risks including their multilevel cost and effect relationships. The results of the risk evaluation can help, e.g., to picture a risk portfolio of a project and allow it to be compared with another.

While mathematically and statistically exact methods for risk evaluation are applicable for the banking or insurance industries, these can not be considered the typical risks of the building industry.

\subsubsection{Risk control}

Risk control is the active manipulation of the risks determined within the scope of the risk analysis. Measures of risk handling can be either cause or effect related. Cause-related measures should avoid or diminish risks, while effect-related measures serve to reduce or safeguard the amount of loss to be expected in the case of risk [3].

\subsubsection{Risk monitoring}

Risk monitoring is the continuous operative control of the effectiveness of the risk control measures. It is not the goal of risk management to completely eliminate risks from the project. Risk monitoring helps to guarantee that the risk position of the project corresponds to the risk situation targeted. This task is supported instrumentally through variance analyses. The internal control system is a component of risk monitoring. The ongoing monitoring of the early indicators takes place by each of the persons responsible and by recurring risk verification.

\subsubsection{Control of the goal}

Measures for control must be taken after the identification, analysis and evaluation of risks. The control process can be subdivided into these sub-processes: designation of the target, designation of the actual, target/actual comparison and variance analysis. Within the scope of the monitoring as permanent process, the risk identification, analysis, and control is monitored 
to see if the implementation of the risk control takes place accordingly. Steps are then to be initiated to determine the causes in discrepancies between an actual and targeted risk situation. The risk strategy must then be adjusted or revised based on these findings.

Risk management in projects therefore implies a permanent advancement of the risk management system based on the results of project analyses.

\subsection{Quantification of risks}

The quantitative evaluation of risks represents a great difficulty for many companies. The evaluation of the risk is based primarily on historical loss data. These are frequently missing because they were not systematically collected in the past or not available in a form that could be evaluated.

However, quantification of the risks is a necessary condition for risk comparison and for the estimation of the possible consequences for the company and its goals [4]. The quantitative amount of the individual risks is required information for the derivation through risk aggregation of the total risk amount and with it, the individual capital requirements, the insolvency probability and the appropriate rating of a company.

The most transparent quantification requires the most detailed documentation of the manner of risk value identification possible.

Cause- effect relationships determine the action of certain risks on planning sizes. These represent the link between the quantifiable risks and the company model. It is therefore possible that a risk works simultaneously on several planning sizes. The analysis of a project at the close of a project gives essential information on where process errors, inadequate qualifications, lack of customer communication or other criteria endanger the project success. Therefore, the aggregation of the knowledge from the postmortem analysis is an important element of risk management.

\section{The post-mortem analysis as a tool for the identification and evaluation of project risks}

The post-mortem analysis serves for the collection of experience in organizations. It enables the identification and processing of experiences in the field of projects.

Details such as uniqueness, lack of standardization, change in project participants and high complexity should particularly be considered within the scope of projects. High complexity leads to the fact that the connections between individual occurrences and the resulting consequences can not be intuitively grasped.

\subsection{Explanation of the post-mortem analysis}

The post-mortem analysis should be a structured ritual at the end of every project. Strengths and weaknesses in the project operation are identified in this way. It is the impetus for the following project; the findings go into the project planning.

In addition, it can help to recognize recurring models in project development that stand in the way of an improvement process. The execution of a postmortem analysis aids the individual project participants in the development of personal knowledge; learning comes from information.

The processes occurring in the project are the focus of the PMA. Defined processes determine those activities and procedures that are necessary for a common understanding of undisturbed work progress. This involves the collaboration of the project team, the content, the sequence as well as the form and the content of the results of the project acquisition and of the project execution [5]. If there are defined processes of the project management in companies that contain quantitative goals and the control associated with it, the risk of failure decreases. At the same time, the performance quality increases with the control and the integration of processes determined by management.

The project review now offers the opportunity to discuss the quality and implementation of existing processes and to identify possible improvements.

\subsection{How a post-mortem analysis takes place in the project}

The post-mortem analysis must be done via an expert or an expert system. The expert must know the project operations in detail.

It must be clarified when the post-mortem analysis is conducted and who participated in it when a postmortem analysis is executed.

As a rule, the PMA workshop takes place at defined project milestones or at the end of the project. A moderator leads the procedure; the members of the project team, manager and possible customer representatives are additional participants. 
The PMA process is made up of five steps:

1. Identifying company success factors Success factors of the company can be cost and schedule compliance, high performance quality, experienced employees, etc. The goal clarity of improvement measures is sharpened by the examination of the processes in connection with the success factors of the organization.

\section{Determining basic conditions}

Projects come about under different boundary conditions, demands and influencing variables. The heterogeneous field also has effects on the way in which a PMA can be conducted successfully and efficiently. The goal must be to come to the conclusion with minor costs and charges to the employees of the organization unit examined. Therefore, the method of execution of a post-mortem analysis should be adapted to the form of the organization examined. The PMA should be conducted differently depending on the size of a project. In practice, differentiation in small to medium projects with up to 30 project employees and in large projects with over 30 project employees proved to be of value.

3. Designating objective and subjective data Costs, deadlines and qualities count in the objective data in projects. Subjective data involves, e.g., perceived customer satisfaction, communication between the participants, collaboration in the team, personal advancement of the team members, motivation and commitment. Several methods are available for the collection of the data, which are explained in more detail below.

4. Collection of experience

The results of the post-mortem analysis are analyzed. The assessment of the findings can result in a strength/weakness profile. This documents the specific advantages of the project course as well as the detectable deficiencies that either lower the efficiency and safety of the project development, or in the worst case, endanger the project goals.

5. Creation of a catalog of measures

All measures suggested in the strength/weakness profile on the different process themes are brought together in a catalog of measures. The estimated implementation expense and the anticipated implementation length are determined with regard to each individual measure. Priorities are determined for the measures that are oriented to the success factors of the company.

In conclusion, work packages for the improvement of the processes are bundled together when the measures are defined and the need for action is determined. Efficient implementation is important for the success of these measures after conclusion of the post-mortem analysis.

\subsection{Methods used}

An essential component of the post-mortem analysis is the execution of a workshop on the project history. In the literature, this step is called the most important step in the process [6].

The following methods are used to gain information:

- Interviews

- Moderated group discussions

- Questionnaires

\subsubsection{Interviews}

Interviews deliver the first global evaluation of the project success from the view of different groups. As a rule, the practical level and the contact level are analyzed in interviews. Questions on the satisfaction of the contractor organization, on the organization of the client, on the users of the project result and on the project team are at the center. A judgment of the project manager with regard to his technical, administrative and social competency occurs.

The involvement of all hierarchy levels directs the necessary attention to the meaning of especially important processes. A balance between the perception of the management and the perception of the employees can take place in this way.

\subsubsection{Moderated group discussions}

In addition to the interview with standardized questionnaires, which is especially adapted for large samples, a moderated group discussion can be a better choice with smaller groups. One handicap of group discussion is that opinions are not expressed openly in the group, especially when there is an authority figure or miscellaneous connections exist.

There are different techniques for the implementation of moderated group discussions. In particular, the KJ method and Root Cause Analysis are used within the scope of the post-mortem analysis.

The KJ method is named after the Japanese ethnologist, Jiro Kawakita; it is also known by the designation of problem landscape. In the process, a moderator asks the participants to find information on a 
defined problem and to write it up on cards. These cards are then ordered according to similarity in categories and clusters. All cards of a cluster are combined; the team looks for relationships and connections between the clusters. These are substantiated and graphically documented. The result of the KJ method is a deeper understanding of the inner connections of a problem. A search for solution should be directly attached to it.

The Root Cause Analysis, also called Ishikawa Diagram or Fishbone Diagram is used for the systematic identification of problem causes. In this connection, all possible causes producing a certain effect are separated into chief causes and secondary causes. Graphic structuring of the causes that enables a clear overall view follows afterwards. In this way, problem causes are identified as completely as possible and their connections graphically represented (Fig 2).

\subsubsection{Questionnaires}

Interviews can be done with the help of questionnaires. The advantage of this is comparability between the projects results.

As a rule, a standardized and structured questionnaire is used for the written interview. All persons interviewed receive the same questions presented in structured content sequence. Open questions are particularly suited for a post-mortem analysis, i.e., questions without answer defaults. The assessment of open questions is time-consuming, since the answers must be categorized and combined with similar answer models. However, aspects can also be explored in informal discussion that largely elude a written interview.

\subsection{Advantages and disadvantages in the use of the post-mortem analysis}

\subsubsection{Advantages}

The use of the post-mortem analysis for the assessment of projects in comparison with other methods primarily offers the following advantages [7]:

- Identification of structures for the improvement of the process;

In principle, the employees reflect on their own methods of operation and at the same time receive feedback from other team members.

Connections in projects that have led to problems, so-called risk models, are revealed in this way. The employees also become acquainted with those project management methods that have proven positive in the project. In this way, frequently repeated mistakes and problems can be avoided in future projects.

- Development of the team members;

Individual experiences that cannot be captured in written form are shared with the group in open discussion. In addition, the individuals learn from the experiences of the group. Fig 3 demonstrates this.

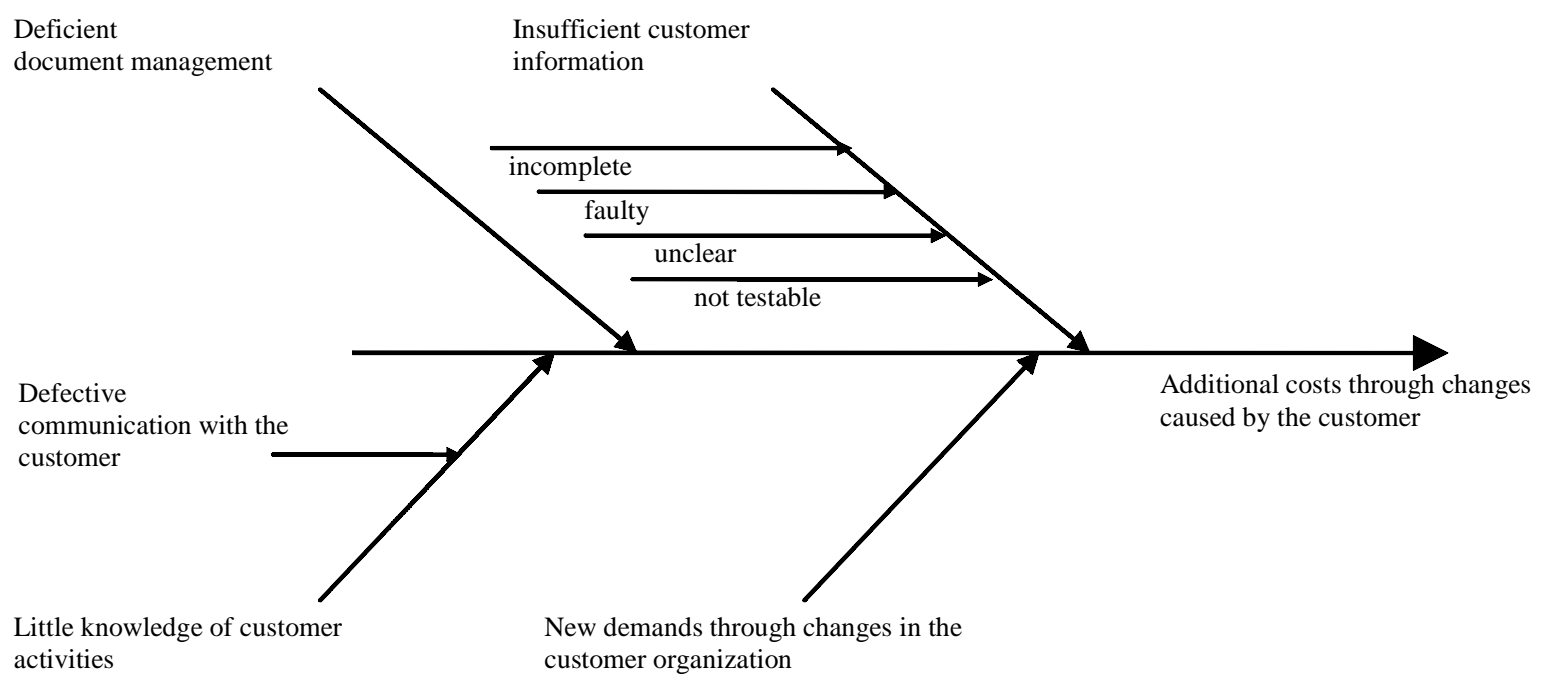

Fig 2. Ishikawa Diagram for altered customer demands 


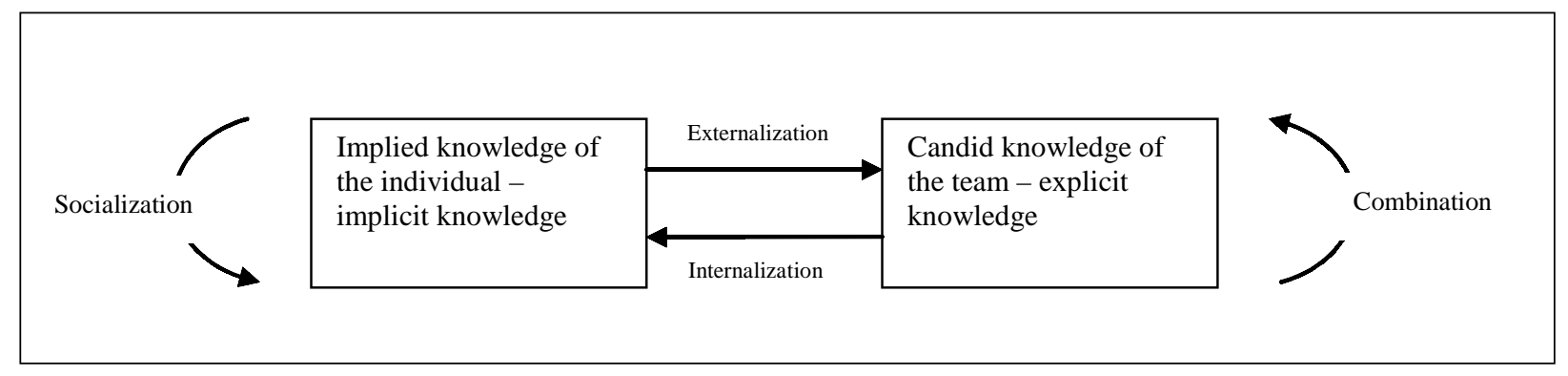

Fig 3. Learning in post-mortem workshops

- Planning of improvement measures; The key risks that threaten the success of the project are uncovered and documented within the scope of the project review.

Approaches for improvement and ideas for risk handling frequently result from the comparison of several project retrospectives. Constructive suggestions for future projects are frequently generated in the course of the post-mortem analysis by the better understanding of the team members.

\subsubsection{Disadvantages of the post-mortem technique}

- Incomplete project review;

The quality of the post-mortem report is dependent on the compilation of the statements of the individual team members. The goal is the most accurate illustration of reality possible.

The individual team members do not often have a complete overview of the total project. The only project factors then considered to be important are those that they confront themselves. Or these factors are represented as being more important in order to emphasize their own role in the project.

- Conflicts of interest;

This leads to concealment of information. Personal mistakes in the project could be concealed out of anxiety about negative consequences. Conflicts of interest between the project participants are pictured in the postmortem process. On the other hand, mutual interests can balance each other again through the composition of the post-mortem team.

- Grievances in the project are frequently revealed in retrospectives that lead to individual complaints. The criticism of the recipient contained in the complaint, however, can lead to the fact that the person criticized is irri- tated in such a way, that he no longer participates content-wise in the workshop.

\section{Use of the post-mortem analysis in the risk management of building projects}

\subsection{Construction management focus}

The process in which a structure is drafted, built and used is best described in chronological sequence on the basis of the life cycle of a structure. Buildings of the commercial construction sector, which serve as places of production, commerce or storage, but also as office and administration buildings are at the center of the following observations. The construction process is separated roughly into three phases - project development, planning and realization phase, as well as the usage phase. At the center of these considerations is realization with the bid and the awarding of the construction work contract, which we summarize with the term of construction management.

In contrast, many procedures take place at the same time in the planning and realization phase. All necessary plans are prepared by the each of the specialists. The executive companies create the structure in accordance with these plans. The selection of those participating in the planning frequently takes place within competitions. Different criteria lead to the decision for or against the participants.

Since many procedures occur simultaneously in this phase and different participants work with and sideby-side with one another, there is a high coordination cost.

In addition to the builder, additional hierarchicallyorganized groups participate in the construction project; architects, building engineers, statisticians, and depending on the particular project, additional specialists must be coordinated in the planning. Different companies from miscellaneous trade groups collaborate again in the execution with the subcon- 
tractors selected by you. Different standards of knowledge and goals lead to misunderstandings and conflicts. An error, which emerges in one of the partial stages of the procedure, can lead to delay, and in the worst case, to a standstill of the entire project.

Risks in the building industry can be divided into the following types:

- Environmental risks

- Technical risks

- Scheduling risks

- Legal and contractual risks

- Financial risks

- Management risks

There are internal as well as external risks in the process. Internal risks come from the whole structure, from partial buildings and/or the construction process and the participants. External risks are factors that can not be influenced by the project participants or only with great difficulty, since they impact on the structure and/or the construction process from the outside.

\subsection{Possible applications of the post-mortem analysis in construction project management}

At the present time, the possibilities of obtaining information from completed projects are overwhelmingly used with regard to project costs.

It is very common in the building industry that cost data banks are established from the project assessment. Since a structuring plan is available with DIN 276 , storage of the data ascertained is possible and reproducible, which allows utilization in later projects. Comprehensive key data systems that include more than cost data are very rare in practice. Ascertained project key data can be used not only for the analysis of completed projects, but can also be included in the planning process.

The German Federation of Project Managers are aware of the partial service of a project chronicle. Indications of improvement possibilities in ongoing and future projects are gathered herein, through compilation of the essential data on the project structure, construction and operation organization as well as project parts [8].

The previously used methods of project assessments in construction projects do not satisfy the demands of integrated risk management.

The use of the post-mortem analysis can be an essential tool of risk analysis and in planning new projects. The objective is to improve subsequent projects with the experience gained.

Based on the procedure as described under Point 3.2, the post-mortem analysis approach is represented in the engineering firm with focus on the performance of the construction management.

\section{Success factors of the company}

The construction manager acts as the responsible person for the quality, costs, and deadline criteria. The qualified employee is at the center of the performance. Project management methods are used for service provision that must be adapted to the respective project data. Communication with the contractor organization is essential. Since large and complex construction projects extend over a longer timeframe, change requests and suggestions for improvement frequently arise.

\section{Establishing basic conditions}

A timeframe must be defined for the project review and the execution of the project workshop according to the size of the project. The selection of participants plays an important role in the success; it should include the following groups:

\section{Project management}

Representatives of the planners

Representatives of the specialized planners

Representatives of the builder

Representatives of the users

\section{Ascertaining objective and subjective data}

Objective project data comes from the project cost planning and scheduling.

Within the scope of the post-mortem workshop, the above are ascertained with the help of the techniques described above. Possible topic focal points could be:

Completeness of the planning criteria, planner selection, design, structure functionality, form of contract, contract award process, technique planning, collaboration with the builder, collaboration with the user, collaboration with the executive firms.

\section{Collection of experience}

The following illustration represents a section from the results of a workshop for project review (Fig 4). It involved a large project for the producing trades with very short construction time and high user demand. Members of all participating groups, representatives of the builders and of the users, representatives of the planners, of the project managers and of the construction management were interviewed. The starting points for the subsequent creation of a catalog of measures are detailed strengths/weaknesses profiles. 


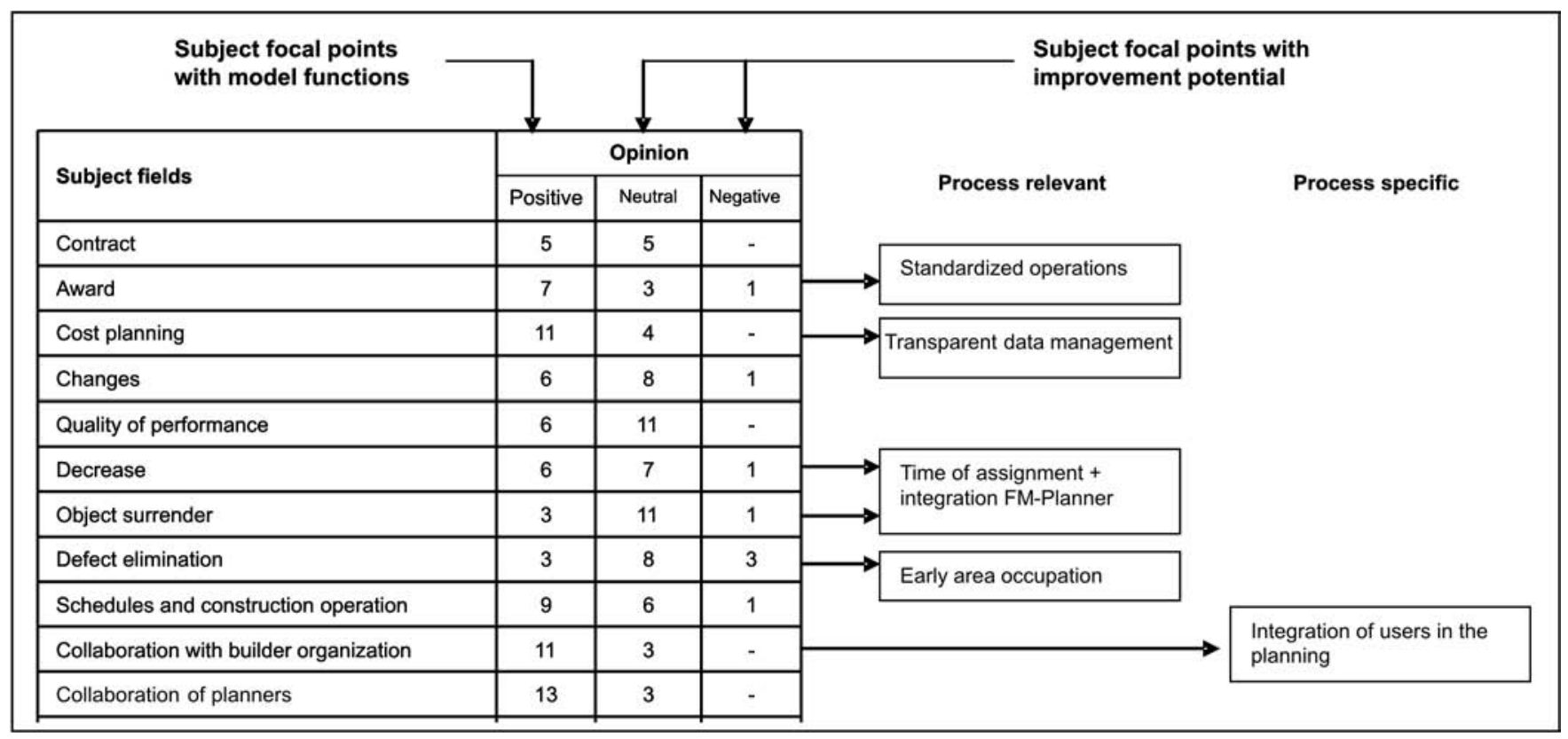

Fig 4. Section from a strengths/weaknesses profile of a large project

They document the specific advantages of the processes, as well as the detectable deficiencies, that either lower the efficiency of the project development or in extreme cases, lead to the endangering of the project goals. In the existing case, problems arose primarily from the early acquisition of the object by the user, which was not known to the planners and the construction management in this area. In subsequent projects, special attention should also be paid to the schedule planning of the initiation phase as well as to the communication with the user to lower the risk to customer satisfaction. The procedure within the scope of cost planning and the transparent data management were seen as positive in the existing project. Therefore, the cost planning tools employed can also be used in subsequent projects in a similar way.

5. Creating a catalog of measures

All measures suggested within the scope of the strengths/weaknesses profile are brought together into a catalog of measures. The subject areas can be ordered in a portfolio of needed actions according to their optimization requirements. Process topics that urgently require further development can be represented in review form to improve the risk structure of the organization.

As the next step, work packages are bundled for the implementation of the measures in accordance with the measures portfolio. These contain project elements and essential content of the procedure, e.g., personnel, length, steps to be carried out, etc.
Tools for risk handling for the future are developed from the aggregation of the results. These can be check lists, operation guidelines for the project managers, risk costs-databanks, etc.

The identification of early warning indicators for risks plays an important role in later projects. Early warning indicators can support risk controlling in the timely identification of relevant changes and emerging goal lapses. So, e.g., a planning delay as a result of delayed plan deliveries can be an indication of impending project changes and thus of a change of the scheduling and financial risk situation.

\section{Conclusions}

The post-mortem analysis can be used successfully as an instrument for risk identification and evaluation. One result of the PMA is the identification of process errors and failures. The findings are entered in a risk catalog for future projects.

In addition, the post-mortem analysis also serves to support learning within the organization. In every project, the team members gain new knowledge and experiences that can be used in future projects. Explicit knowledge of the organization comes from implicit knowledge of the project manager.

However, a condition for the successful post-mortem workshop is a corresponding project culture that enables criticism to be expressed positively and also to be accepted positively. 
The advancement of the process steps and the deduction of recommendations for upcoming projects follow the compilation and analysis of the problems originated in the project. This increases the quality of the construction management performance in the long-term, and the costs of handling the risk also drop. An efficient risk management system offers the company the opportunity to improve its market position.

\section{References}

1. DIEDERICHS, M. Risikomanagement und Risikocontrolling (Risk Management and Risk Controlling). Verlag Vahlen, 2001, p. 14.

2. SCHIEG, M. Risk Management in Construction Project Management. Business Economics and Management, 2006, Vol VII, No 2, p. 77f.

3. GÖCKE, B. Risikomanagement für Angebots-und Auftragsrisiken von Bauprojekten (Risk Management for Bid and Order Risks of Construction Projects). DVP Verlag, Wuppertal, 2002, p. 169.

4. GLEISSNER, W.; ROMEIKE, F. Risikomanagement, Umsetzung, Werkzeuge, Risikobewertung (Risk Management, Implementation, Tools, Risk Evaluation). Haufe Verlag, 2005, p. $192 \mathrm{ff}$.

5. LEBSANFT, K. Projektmanagement-Assessment in der Praxis (Project Management - Assessment in Practice) p. $2 \mathrm{f}$, in Projekte erfolgreich managen (Successful Managing in Projects), ed. GPM, Schnelle, Reschke, Schnopp, Schub.

6. KERTH, N. L. Post Mortem, Projekte erfolgreich auswerten (Evaluating Projects Successfully), p. 77f.

7. NELSON, He. Looking Back to Move Ahead: The Business Value of Retrospectives. In Proceedings of the NCUR, 2006, North Carolina, p. 2 f.

8. DVP, Projektmanagementleistungen in der Bau- und Immobilienwirtschaft (German Federation of Project Managers, Project Management in the Construction and Real Estate Industry), AHO No. 9, p. 178. 